Ethiopian Journal of Environmental Studies \& Management 9(Suppl. 2): 951 - 966, 2016.

ISSN:1998-0507

Submitted: August 13, 2016

doi: http://dx.doi.org/10.4314/ejesm.v9i2.2S

Accepted: December 14, 2016

\title{
VISUALIZATION OF TEMPORAL ASPECTS OF TSETSE FLY ERADICATION IN ZIMBABWE ON THE WEB
}

\author{
MARUZIVA, R. \\ Department of Rural and Urban Planning, University of Zimbabwe \\ Email: maruziva00725@alumni.itc.nl
}

\begin{abstract}
Visualization of tsetse eradication operations that have been going on since early $20^{\text {th }}$ century is what many people would like to do if possibilities are provided. In this assignment, available data are analysed and viewed in the three tsetse eradication programmes. Zimbabwe is divided into three area categories; infested, reclaimed and pre 1896 tsetse free zone. Information on where eradication operations were carried out and the technologies that were applied for each year were extracted and mapped within its operation programme. Technologies applied were viewed individually and their positions compared with the fronts before and after they were applied. Pattern of how they are applied in time was provided in the animation representation. Further information on areas where different techniques were applied on different years is interactively visualized. Visualization of infestation changes in time was also provided by animation representation. Visualization of eradication operations were disseminated on the web. From the available data, it was possible to visualize Zimbabwe in three distinct categories: infested, reclaimed and the area that had never been occupied by tsetse flies. Visualization of tsetse fly eradication processes was possible in three sections that identified the sequence of eradication. It has been possible to visualize the change in technology in terms of techniques used. Accessibility of tsetse fly eradication was provided by the web.
\end{abstract}

Key Words: Visualization, Tsetse fly, Eradication, Infested, Reclaimed, Disseminate

\section{Introduction}

Tsetse flies transmit trypanosomiasis which causes nagana (fatal wasting disease) in cattle and sleeping sickness in human. A lot of techniques have been used in attempts to eradicate them over a long period of time, dating back to 1919 (Du Toit 1997) and (Lovemore 1999). Thus the time game hunting was used after noticing that the death of animals that provide food to tsetse flies due to rinderpest disease in 1896 resulted in the disappearance of the flies. Experiments on aerial and ground spraying were carried out before the Zimbabwe war of independence broke out. During the war in the mid 70s, it was impossible to apply these techniques, resulting in tsetse flies 
reinvading most areas that were once cleared of the flies (Chadenga, 1992).

Post 1980 (Independence of Zimbabwe) saw eradication efforts being intensified. There were three eradication programmes that were implemented-:

- $1980-1985$

- $1986-1991$

- $1992-1998$

The last two were being partly donor funded. The main objective of the programmes was to reclaim the land lost to tsetse flies during the war of independence. The following techniques; aerial spraying, ground spraying, cattle treatment and targets were employed. Targets are 1.7 x 1 metres blue-blackblue cloths attached to metal frame that is pivoted on a metal driven upright into the ground such that its free to rotate. They were then treated with deltamethrin suspension concentration (Shereni, 1984.)

\section{Background and eradication techniques} applied

Tsetse flies infested almost half the country in the mid- $19^{\text {th }}$ century as can be established from records from explorers, missionaries and hunters. The infested areas were divided into two distinct belts, the Zambezi belt and the Limpopo belt, separated by the plateau of relatively high elevation. The maximum affected limits ran close to $1200 \mathrm{~m}$ height above sea level avoiding, cold high altitudes as shown in figure 1(du Toit, 1997) and (Lovemore, http://www.sacema.com/uploads/tsetse/ts etse-project/tsetse-project-reprint1387.pdf

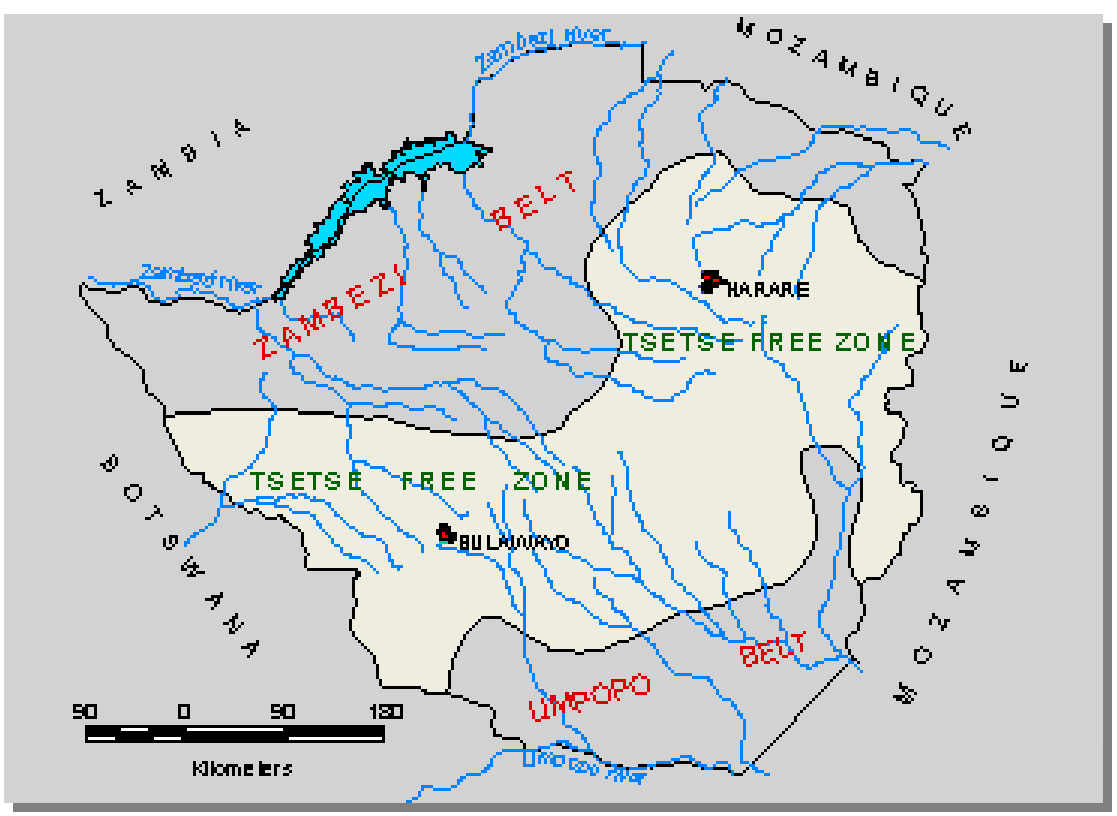

Figure 1: Tsetse fly free belt pre 1896 (in light yellow)

\section{Rinderpest Panzeotic 1896}

The disease destroyed cattle, game animals like buffalo, kudu, eland, bushbuck, warthog and bush pigs that were food source for the tsetse flies. This resulted in the disappearance of the flies in the Limpopo belts and contraction into 9 small areas in the Zambezi belt before 
the turn of the century. By 1925 Host food had recovered followed by tsetse flies in the Zambezi belt and 1950 tsetse flies reappeared in the South East.

\section{Game Eradication 1919}

First "game eradication" experiment in Africa was carried out between the Shangai and Gwayi rivers where Trypanosomias was on the rise in both communal and commercial farms. The experiment was successful by 1923 . The technique was then applied to other areas south of the zambezi escapment from 1924 to 1940 but then with fences constructed $16 \mathrm{~km}$ apart were introduced between Manyame and Angwa rivers, now Doma commercial farming area in1924, Chegutu 1926 and Mupfure river 1931. Although the technique was successful, it received public criticism and was therefore forbidden to be used for any offensive purposes except where Settlements needed protection and maintaining a static tsetse front (line that demarcates infested area and claimed area) only (Child and Riney, 1987). http://www.africabib.org/htp.php?RID=1 19547481

\section{Bush Clearing 1932-1957}

In the south eastern border with Mozambique, bush clearing technique was carried out between 1932 and 1957 to prevent tsetse flies spreading into Zimbabwe by clearing a barrier $84 \mathrm{~km}$ long by 1,5 to $2,4 \mathrm{~km}$ wide.

\section{Second World War}

This war made it difficult to maintain control measures during the latter years of the war and immediate post war years. This resulted in tsetse invading the Hurungwe district and other areas along the Zambezi valley. Eradication operations were intensified by constructing game fences, for game elimination and cattle fences that prevented cattle from entering tsetse infested areas.

\section{Aerial Spraying 1953 - 1957}

From 1953 to1954 aerial spraying 4\% $\mathrm{BHC}$ in dieseline insecticide was first tried in Hurungwe with unsatisfactory results.

In 1956 the technique was used again at Kariba and at Lubi valley in Binga district in 1957.The results were generally satisfactory. In all cases the purpose was to reduce tsetse population and danger of human trypanosomiasis infection.

\section{Ground Spraying Trial 1960}

The experiment which was carried out at Maseme using $3.7 \%$ dieldrin insecticide proved to be very successful that it was declared to be the only method to be used. This did not last long before most infested areas expanded because the capacity for ground spraying was not yet in place. At this time bovine trypasonomiasis was occurring in most cattle pastures and reinvasion of southern lowveld was advancing rapidly. In 1962 and 1963 experiment was undertaken to restrict elimination to animals proved to be the blood meal. Tsetse was reduced by $98 \%$. In 1964, the objective was to regain the tsetse belts by selective hunting, setting up natural host-free and cattle-free fenced corridors as well as increasing spraying capacity. The insecticide DDT was then used in 1968 instead of dieldrin.

Aerial spraying was again used in 1974 and 1975, this time with better results than before. By 1975 achievements of this operations which started in 1964 were that considerable area had been reclaimed, the northern belt had been split into two at the eastern end of lake Kariba, area between Mazowe 
and Gairezi rivers were cleared of tsetse fly and the fly had been driven 90 kilometres into Mozambique, leaving the southern lowveld free of tsetse.

\section{Zimbabwe War of Liberation}

The successes of 1975 were short lived as the war made it difficult to continue with the operation without danger. Tsetse flies reinvaded most of the areas and the operations remained inactive until at independence in 1980 when peace prevailed again.

\section{Post War Periods}

Host-free and cattle-free corridors could not be re-established because fences were badly damaged during the war. From 1980 - 1985 ground spraying and aerial spraying eradication techniques were used.

\section{European Economic Commission Programs}

(a) First Phase, 1986 - 1991:

The objective was to reclaim the land lost to tsetse flies in the northern districts and prevent reinvasion from Mozambique. Techniques used were:

Aerial spraying, applied in three separate operations, the first in 1986, the second in 1987 used endosulfan insecticide and the third in 1988 used Deltamethrin insecticide as experimental.

Ground spraying applied in 1986 and 1988 using DDT insecticide.

Targets, mid 1986 to mid 1988.

Ground spraying and targets were also used as barriers to limit reinvasion. Targets were mounted for $353 \mathrm{~km}$ along the Mozambique border as a defensive measure against re-invasion and application of deltamethrin to all cattle depastured immediately behind the barrier (Shereni, 1984).

Targets were also used in rough terrain. (b)Second Phase, end of 1992-1998
Northern, north eastern and eastern districts operations

Defensive measures were put in place to safeguard the reclaimed areas and protect the cattle near the infested areas.

Targets and deltamethrin-treatment of cattle continued throughout the second phase. Some donor-funded projects were also involved like the Integrated pest management initiative (IPMI) 1991 1996 and Cattle management practices, implications for tsetse control 1998 2000 both DFID funded.

\section{Problem Definition}

There was a lot of temporal information on tsetse fly eradication that shows limits (boundaries), techniques used, their locations and type of chemicals applied. The information was contained in analogue maps and reports. There was no possibility of getting digital files of the information from the branch or from their web site. The information was therefore not easily accessible by most potential users like scientists, university students, farmers, non governmental organization, donor community, health providers, general public and government departments involved in resettlement and land use planning, The maps on URL: http://www.africaonline.co.zw/vet/tsetse. html/trypanosomiasis.html had the following problems; one had no explanation of the symbols, the other had been reduced too much to be legible. Regionally, spatial data on tsetse eradication were not disseminated well on the web. The only other country with such maps was Botswana but navigation through the maps was not provided. Pages were not linked to each other. When a page was open, you could not go 
back to home page but you had to close the page and open another one.

URL:

http://www.fao.org/paat/html/body_bwa. $\underline{\mathrm{html}}$

Data could be represented in other ways that facilitate information extraction by the user.

The objective of the study was

(a) To visualize tsetse fly eradication process and provide information on:

- Land reclaimed and that still infested.

- The changes in boundaries over time.

- Techniques used and their locations.

(b) Dissemination of the information through the web to provide:

- Accessibility of information

- Interaction possibilities (e.g. to compare data and find additional information)

- Dynamics (animation)

\section{Study Questions}

- The project will attempt to answer user questions such as:

- What land was/is tsetse infested?

- What land was reclaimed?

- Where did tsetse eradication take place?

- When did tsetse eradication take place?

- How were the operations carried out?

- What techniques were used?

- Where were the techniques applied?

- What happened after the application?

- What insecticides were used?

- What problems were encountered? Any history of problem area?

- Where to get more information?

\section{Methodology}

\section{Data Collection}

The data are required for maps that would provide the user with information on what land is tsetse infested / reclaimed and show tsetse eradication operations of different years and areas covered in each of the three programmes. Identify techniques used, where and when they were used. The maps would also provide information on the changes that took place over time and visualize the pattern of change with possibility of comparing places where different techniques were applied with fronts (boundaries) before or after the technique was applied. Maps can be considered as spatial information system that provide answers to many questions concerning any area depicted (kraak and Ormeling, 1996). The data required would therefore consist of boundaries demarcating infested and reclaimed areas and areas of operations indicating techniques used in different years. The data available was from digital files acquired by digitising from analogue maps and from reports, which needed to be analysed to find out which of the described techniques and locations had been mapped. The data contained in digital files were analysed to establish if they were the required and correct data.

The data were supplied in two categories, the line themes and the polygon themes for each operation year. To define what these lines and polygons represented, themes were classified according to their unique values in ArcView to enable evaluation of their contents in respect of boundaries indicating the approximate position of tsetse infested/reclaimed areas for different years and types of eradication techniques applied. Literature, analogue and screen maps were used to determine what information could be mapped and which one could be linked to the maps at a later stage. This was done by 
comparison of the analogue maps, digital files and description from the literature to establish if the techniques mentioned in the reports have their locations mapped. To get a better overview of all techniques that were applied since 1896 a table was constructed (Table 1). The years in which operations took place were listed in left column whereas the techniques used were displayed in the first row. The techniques that were described and their location indicated on analogue maps or digital files were shown with (yes) and those that were not mapped were shown with (no) as shown in table 1.

From the table it became clear that the location data available for mapping was for post independence Zimbabwe. These data were therefore selected for representation on demo Web site. The data were in digital and analogue. Comparison of the two sources was carried out to identify omissions and errors in digitising. The errors identified at this stage were wrong classification of some areas or lines, into wrong classes, for example area between two ground sprayed areas that was supposed to be reclaimed area was classified as ground sprayed and the ground sprayed below it as reclaimed. Such errors were corrected by editing the tables and correct classes in Arc View.

Table 1: Table showing mapped/not mapped eradication techniques locations

\begin{tabular}{|c|c|c|c|c|c|c|c|c|}
\hline $\begin{array}{c}\text { Years of } \\
\text { operations }\end{array}$ & $\begin{array}{l}\text { Game } \\
\text { hunting }\end{array}$ & $\begin{array}{l}\text { Cattle } \\
\text { Fence }\end{array}$ & $\begin{array}{l}\text { Bush } \\
\text { clearing }\end{array}$ & $\begin{array}{l}\text { Aerial } \\
\text { spray }\end{array}$ & $\begin{array}{l}\text { Ground } \\
\text { spray }\end{array}$ & Targets & $\begin{array}{l}\text { Cattle } \\
\text { treatment }\end{array}$ & Remarks \\
\hline 1919 & no & & & & & & & $\begin{array}{l}\text { Animal/tsetse } \\
\text { recovered }\end{array}$ \\
\hline $1932-57$ & & & no & & & & & $\begin{array}{l}\text { Mozambique } \\
\text { border }\end{array}$ \\
\hline $1940-45$ & no & no & & & & & & 2nd world war \\
\hline 1953- 57 & no & & & no & & & & \\
\hline $1960-65$ & yes & yes & & no & no & & & \\
\hline $1975-80$ & yes & yes & & no & no & & & Zimbabwe war \\
\hline 1982 front & & & & yes & yes & & & Independence \\
\hline 1983 front & & & & yes & yes & & & \\
\hline 1984 front & & & & yes & yes & & & \\
\hline 1986 front & & & & yes & yes & yes & & $\begin{array}{l}\text { Phase 1, plus } \\
\text { EEC funding }\end{array}$ \\
\hline 1987 & & & & yes & & yes & & \\
\hline 1988 & & & & yes & yes & yes & & \\
\hline 1990 & & & & & & yes & yes & \\
\hline 1996 & & & & & & yes & yes & $\begin{array}{l}\text { Phase 2, plus } \\
\text { EEC funding }\end{array}$ \\
\hline 1997 & & & & & yes & yes & yes & \\
\hline
\end{tabular}

Restructuring and Reclassification of Data

In order to be able to choose and manipulate the theme values, all themes were queried and their values turned into separate themes by converting theme into shape files. These new themes were then used to compile new maps with the desired information for example, line defined as 1982 front marks the boundary of infested area and reclaimed areas. The area in front of the line in the direction of 
operation was reclassified as infested area and the one behind as reclaimed land. These lines and areas show changes that had been taking place for different years. Techniques used were classified according to their type, for example aerial spraying, ground spraying. All themes were then symbolised and assigned colour for same features type on all maps for easy identification when compiling required maps.

Analysis of the data from available literature and maps reviled that a lot of data existed. It was then possible to extract the following:

- Three distinct categories pertaining to tsetse eradication; infested, reclaimed and the area that had never been occupied by tsetse.

- Three operational programmes that indicated sequence of eradication process.

- Techniques used in all the programmes

- Locations of areas where eradication took place

- Fronts for different years

- Areas where different techniques were applied many times throughout the years defined as problem areas.

All this information needed to be restructured before it could be used for ease manipulation.

\section{Map Design and Production}

Maps compiled carry information on tsetse limits/fronts (boundary), areas where eradication was taking place indicating technique used, area still infested, area reclaimed as well as the climatic limit that run approximately close to 1200 contour where tsetse flies could not invade because of cold temperatures as shown on figure 1 . These features could be identified in the three tsetse fly eradication programmes.

The maps were compiled for different operational years in relation to the three post-independence eradication programmes.

Mapping in the programme structure help to identify how the eradication was done, being shown by activities of each programme. The following maps were produced

- Operations maps

- Overview maps

- Techniques maps

- Infestation changes maps

- Problem area maps

Map design is a process which starts from the time one decides to make a map by deciding what type of map and data to be represented. Once the general design is acceptable, symbolization, colour and sizes are defined in general. In ArcView, this took place in the view frames when the map objects were made to be coherent. Final specifications could be done, considering the layouts and their output destinations (Table 2). In GIS supported software like ArcView, it was easy to make so many trials before coming to the final design that is able to communicate the message to the user. The maps produced were destined for screen visualization of Tsetse fly eradication. The information to be represented was qualitative therefore the information should appear to be on the same level of importance. An important element to be shown on all maps was the front line that is the main message of these maps, because it demarcates tsetse fly cleared area with the infested area. It also marks where possible danger from tsetse fly transmitted diseases can be expected. The line was central to all 
eradication activities. This line has been emphasised to attract users to the important information on both sides. The three main categories; infested, reclaimed and 1896 tsetse free zone were assigned subdue colours of red, green and brown respectively as shown in figure 2 . No distinct outline has been put to demarcate these areas because their boundaries are approximated.

Table 2: The symbol specifications

\begin{tabular}{|c|c|c|c|c|}
\hline Feature & Type & width & Outline width & Colour \\
\hline Irfested area & Polyzon & & 0 & $v$ lightred \\
\hline Reclaimed area & Polyzon & & 0 & $\mathrm{v}$ light green \\
\hline 1896 tsetse free & Polyzon & & 0 & $\mathrm{v}$ light brown \\
\hline Aerialspraying & Polyzon & & 1 & blue \\
\hline Ground spraying & Polyzon & & 1 & light yellow \\
\hline Targets & Polrzon & & 1 & 파르 \\
\hline Cattle treatrort & Polyzon & & 1 & light bhe \\
\hline Tar get barier & line & 3 & & purple \\
\hline Country boundary & line & 2 & & black \\
\hline Fort line & line & 3 & & red \\
\hline Fivers & line & 1 & & blue \\
\hline Lakes & Polyzon & & 1 & light bhe \\
\hline Lakes outline & line & 1 & & rivers bhye \\
\hline
\end{tabular}

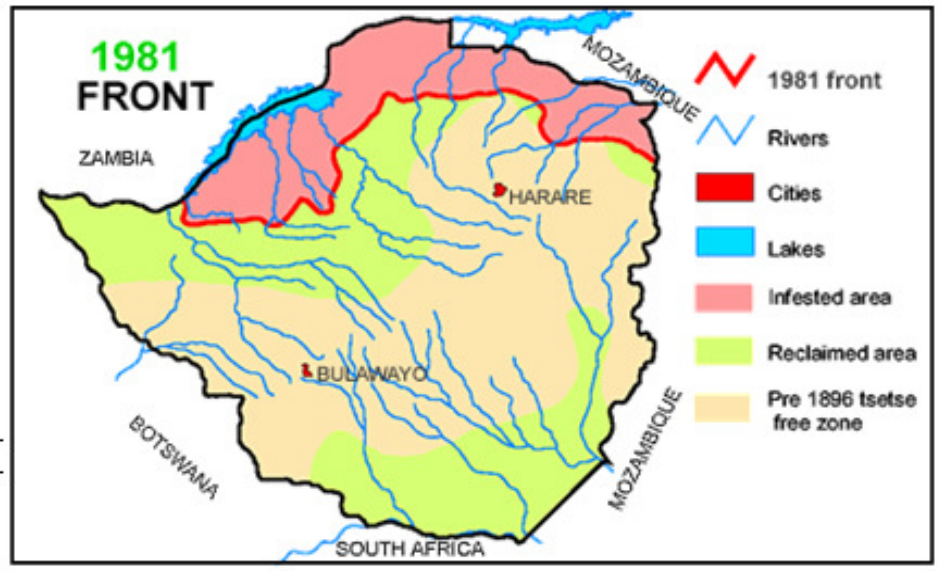

Figure 2: Three categories infested, reclaimed and Pre 1896

\section{Information Selection and Layouts}

Some maps that were produced in the views were processed further in the layout facility of ArcView, where it is possible to add marginal information like title, legend, scale and position and balance the appearance of map elements. Instead of compiling or producing new maps for techniques and infestation changes, it was possible to use the existing views to utilise the facility in
ArcView of switching off some of the themes with information that was not required and make a layout or export the view of the remaining wanted information. Techniques maps, required for animation visualization were made for all programmes by switching off all other information themes except the techniques, fronts, lakes, the cities, rivers and country boundary and the view maps were exported. Only one layout for the 
selected information was made for each technique type. This layout was to provide the legend and the layout structure in Fireworks when map elements were put together and further processed for animation frames.

Maps for infestation changes have all the techniques switched off leaving the three categories of the land classification and front lines for particular year. The maps were processed the same way as in the technique maps.

On noticing a number of different techniques appearing on the same spots a number of times, it became evident that it was an indication of a problem of tsetse flies that were difficult to eradicate. It was also difficult to view them at once. The solution to the problem was to provide a map that would make visualization of the problem possible and also show the technique that was applied and when it took place. Visualization of the surrounding area would help the audience investigate the influence for the problem by identifying similarities in the land use.

In problem areas maps, land use themes were switched off when the circles of $50 \mathrm{sq} \mathrm{km}$ radius had been drawn around the three identified problem areas; Doma, Matusadona and Sengwa. A layout of the Zimbabwe map with the circles was produced and exported. The Zimbabwe map was then zoomed and themes of administrative districts, national parks and safari areas were switched on. The region around the problem areas were projected each at a time, layout made and link switched off after each layout. The layout maps were exported and opened in Fireworks were labelling of districts, national parks and safari areas was done.
Further processes in Fireworks and Dreamweaver were done to add interactivity, animation and prepare for web dissemination to provide accessibility.

\section{Animations Preparation}

Problem Area Map: Slices of all the areas on the country map were created. On all the three maps of the problem areas surroundings, hotspots were created on all the circles that indicate the areas and behaviours of pop up messages were created. Lists indicating the year and technique applied on a particular year were typed on the pop up messages and maps exported as html. In Dreamweaver, a frameset with two frames was created and linked to the button problem areas on the main frameset. The country map was inserted on the left frame and enlarged regional area maps were linked to their respective circles on the country map and targeted to the right frame

Frames were used to create the animation of the techniques used and of the fronts. The display time was linked to world time by assigning speed per year. Variations introduced by the temporal component are presented in a single map and variations in time are not deduced from a spatial sequence but from the actual change in the map image, which can be perceived as movement (Kraak and MacEachren, 1994). The maps exported for this purpose had no legends, titles and names of neighbouring countries as well as the cities. All these elements were brought together when the frames for the animation were being created. A map, for example aerial spraying 1982 was opened in Fireworks, the canvas size was increased in the direction where the legend was to be placed. A map with a legend was opened 
and the legend copied and pasted onto aerial spraying 1982 . The aerial spraying 1982 with the new legend was copied and pasted onto frame 1. Frames to the number required were added. The legend was copied from aerial spraying 1982 map and frame 2 was open with no map but the canvas only, the legend was then pasted on the canvas on frame 2. aerial spraying 1983 was opened and copied. The canvas with the legend only was activated and aerial 1983 pasted on it. Then this process was repeated for all the maps. The names were typed on one map in the frame set and copied and pasted onto the others in the set. The dates on the title were pasted first then edited to show the right date. In the front maps the date on legend was a problem because it was part of the image. The solution was first to erase before pasting the date on the frames. In Fireworks the dates could be typed in frames and pasted to other frames where it could be edited.
Frames of different techniques were exported individually as gif for comparisons but a set with animation frames was exported as animated gif and linked to the animation.

\section{Web Dissemination}

Information on tsetse fly eradication had been mapped. Some information was easy to visualize in series of static maps and single overview maps. Overview maps showed well the places that had been covered but it had been difficult to show techniques applied for different years without overcrowding the map or information overlapping. It was also difficult to indicate how many times a technique had been applied on a particular place. The interactive and dynamic nature of web guarantees that the map in its "traditional" role can be informative and attractive for map users while available functionality supports a solution to the above problems (Kraak, 2001)

\section{WEB DESIGN AND PRESENTATION}

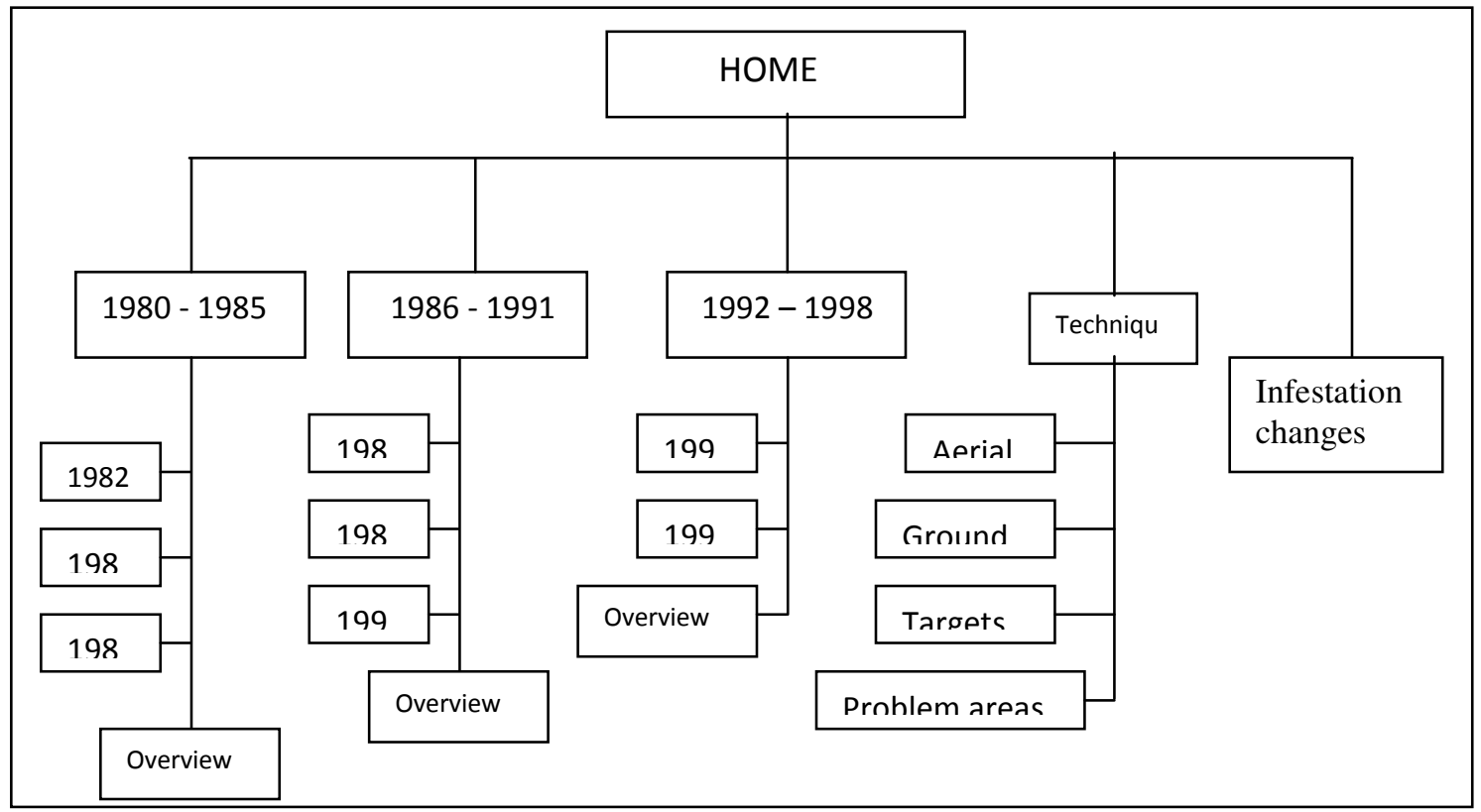


The web has been designed such that the first page carries the contents and tsetse related images. The contents were arranged in the order of eradication programmes and on the bottom are techniques used that can be compared with fronts or animated representation. The problems areas, identified to have different tsetse eradication techniques applied on them many times are placed after the techniques maps.

Infestation changes animation representation with overview of changes in the infested and reclaimed area is placed last as shown in figure 3 .

\section{Results}

The following maps were produced: On all operational maps for different years, techniques applied which also mark location where tsetse fly eradication operations took place were shown by different colours on top of infested area as shown on figure 4. They were placed in front of the front line for that year. Operations for different years have been represented with multiple static maps because it is easy to visualize activities of one year clearly in one map. It is also convenient for a user who wants information on a particular year to obtain it.

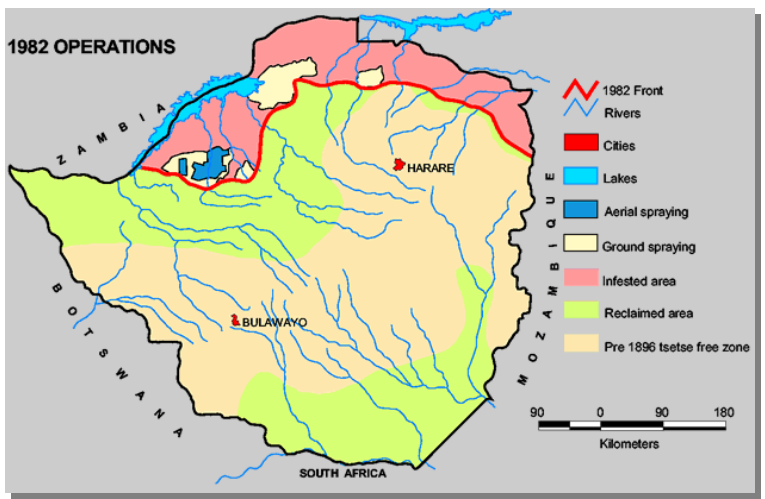

Figure 4: Operations map Single year tsetse fly eradication activities

\section{0 - 1985 Programme}

1982 operation showing post 1981 operation limit as the 1982 front and techniques applied in 1982 in front of the front line.

1983 operation showing post 1982 operation limit as 1983 front and the techniques applied in 1983 in front of the front line.

1984 operation showing post 1983 operation limit as 1984 front and the techniques applied in 1984in front of the front line.

Overview maps have techniques showing total area where operations have taken place in the programme. Single static maps provide the overview of the whole programme showing areas where eradication actually took place and the type of technique used. This would therefore suit the visualization of the whole programme and have a better understanding of total area covered, as well as techniques that were applied as shown on figures 5, 6 and 7 .

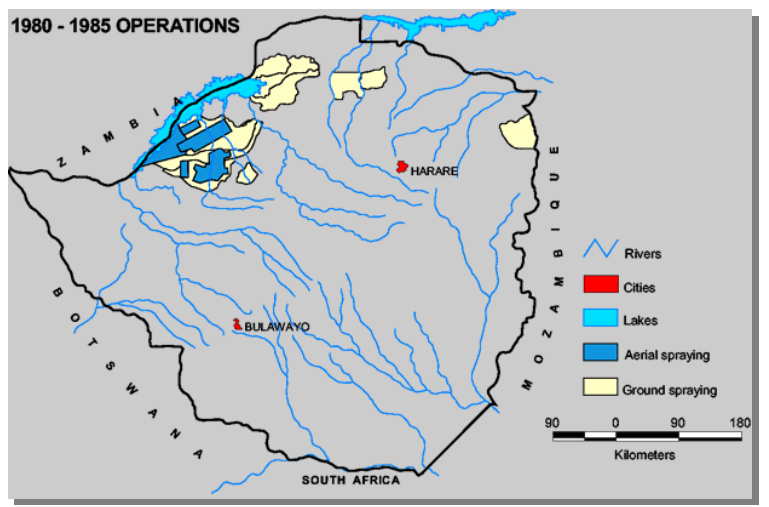

Figure 5: Overview for the 1982 - 1985 programme

\section{6 - 1991 Programme}

1986 operation plus 1987 aerial spraying (data on 1987 front not available)

1988 operation showing 1988 front and techniques applied 
1990 operation showing 1990 front and techniques applied.

An overview map of the programme showing where eradication took place and techniques applied

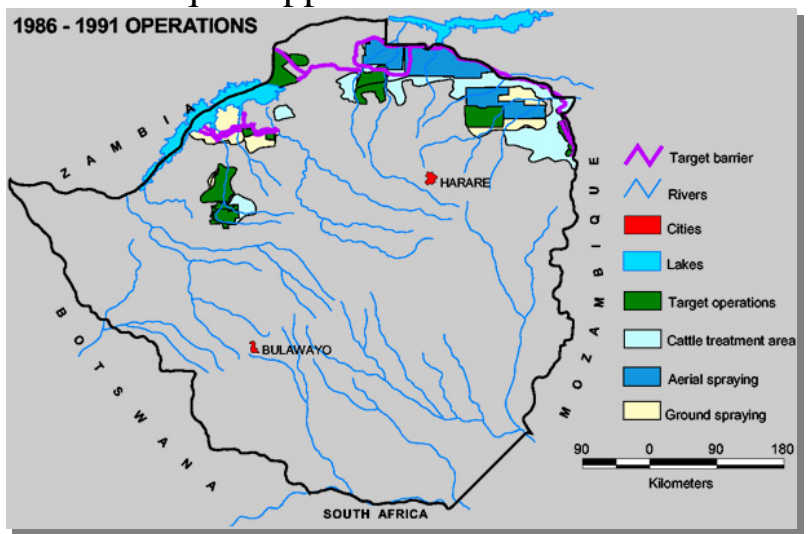

Figure 6: Overview for the 1986 - 1991 programme

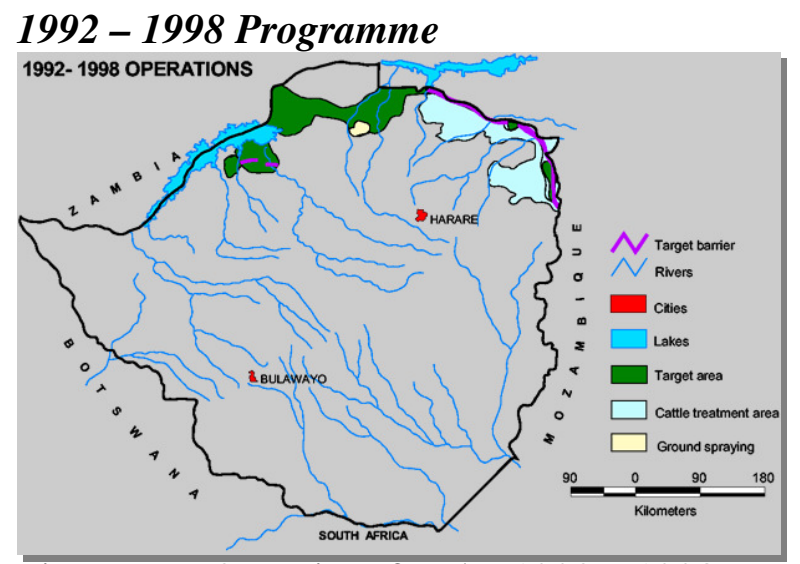

Figure 7: Overview for the 1992 - 1998 programme

In this programme, defensive measures were put in place to safeguard the reclaimed areas by constructing target barriers and treating cattle
1996 operation showing 1996 front and the applied techniques

1997 operation showing 1997 front and the applied techniques

An overview of the programme showing areas where the defensive measures were located.

\section{Technique Maps}

Technique maps have the type of technique and front line for that particular year with the date also clearly marked as shown in figure 8 . In order to visualize the effects of each technique applied at a particular place and the pattern in all the programmes, series of maps for different years have been used to compare with fronts before the application and after the application to see the change at the particular place.

Maps produced for techniques cover the following;

1982 - 1988 aerial spraying showing areas sprayed and fronts for each year 1982 - 1988 ground spraying showing areas sprayed and fronts for each year. 1986 - 1997 targets showing targets operations including target barriers for each year.

No maps for cattle treatment because its used as defensive even in reclaimed areas. These maps enabled users to choose any technique of interest and view where and when it was used. The effectiveness of each technique can be seen by comparing results of where different techniques were applied. 


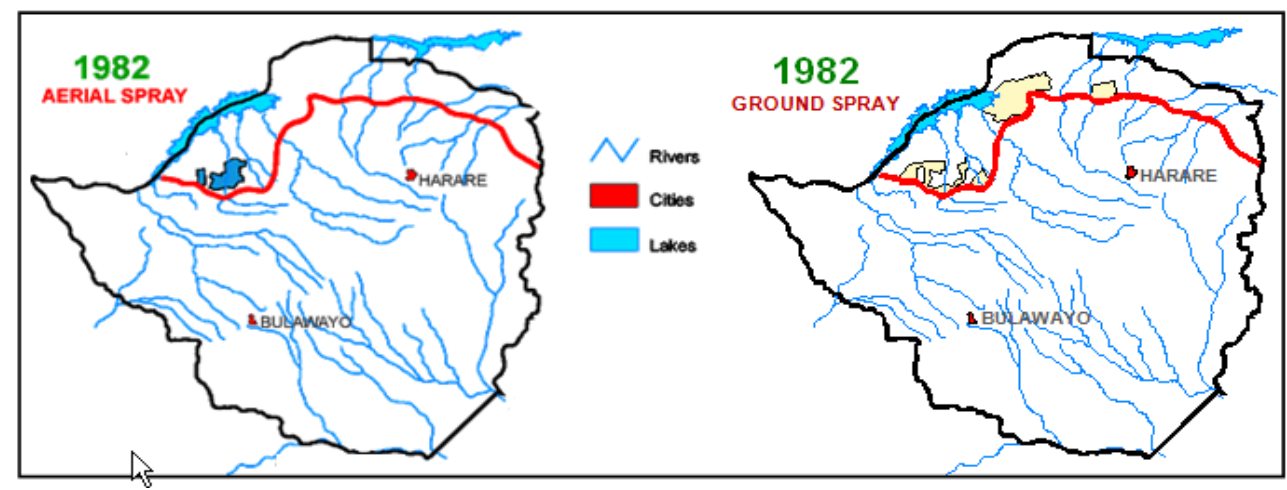

Figure 8: Eradication techniques applied

\section{Problem Areas Maps}

Zimbabwe map indicating problem spots where different techniques have been applied but were not effective. It was noted that the problem areas were near national parks or safari areas.

Problem area maps consist of a Zimbabwe map and one map for each region that contain the problem area. The Zimbabwe map will have the problem areas marked on it that will be linked to the region maps. The region maps have the administrative and land use information like national parks and safari areas. The problem areas were also marked on the region maps and would be linked to mouse over behaviours to display information on dates, techniques and insecticide applied on the area. The problem areas maps were to be used interactively to give information on the area's location in terms of administrative districts and land use as well as information on techniques and insecticides used as shown on figure 9.

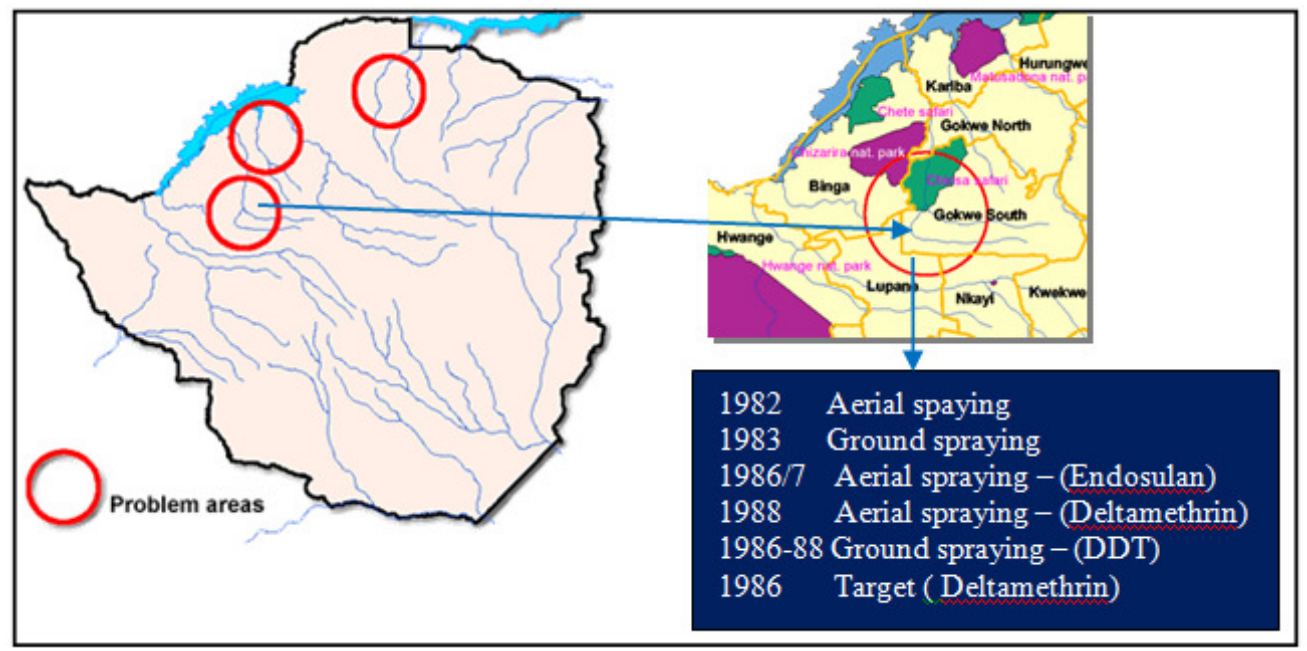

Figure 9: $\quad$ Problem areas map

\section{Infestation Changes Maps}

Infestation changes maps that provide overview of the changes, have three land categories, infested, reclaimed, tsetse free zones and front line for that year as in figure 10 . The dates were marked clearly. 
Infestation changes for all the programmes were represented by frames made from maps on figure 10 for

animation. The display time was linked to world time by assigning speed per year.

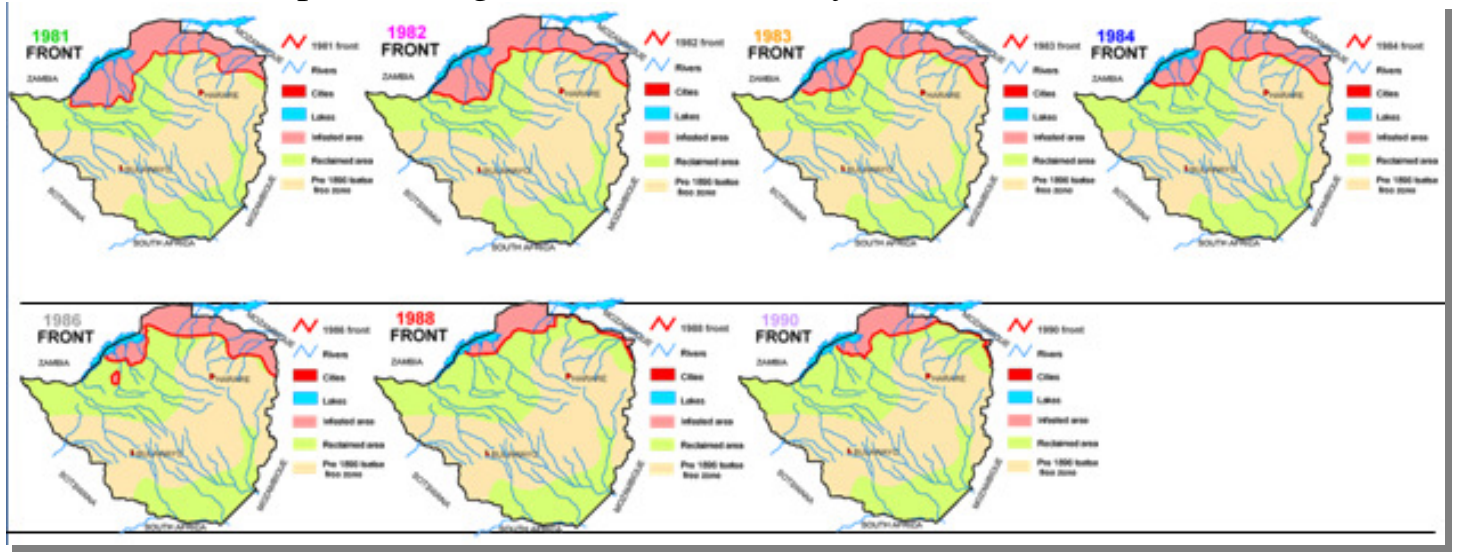

Figure 10: Infestation changes map

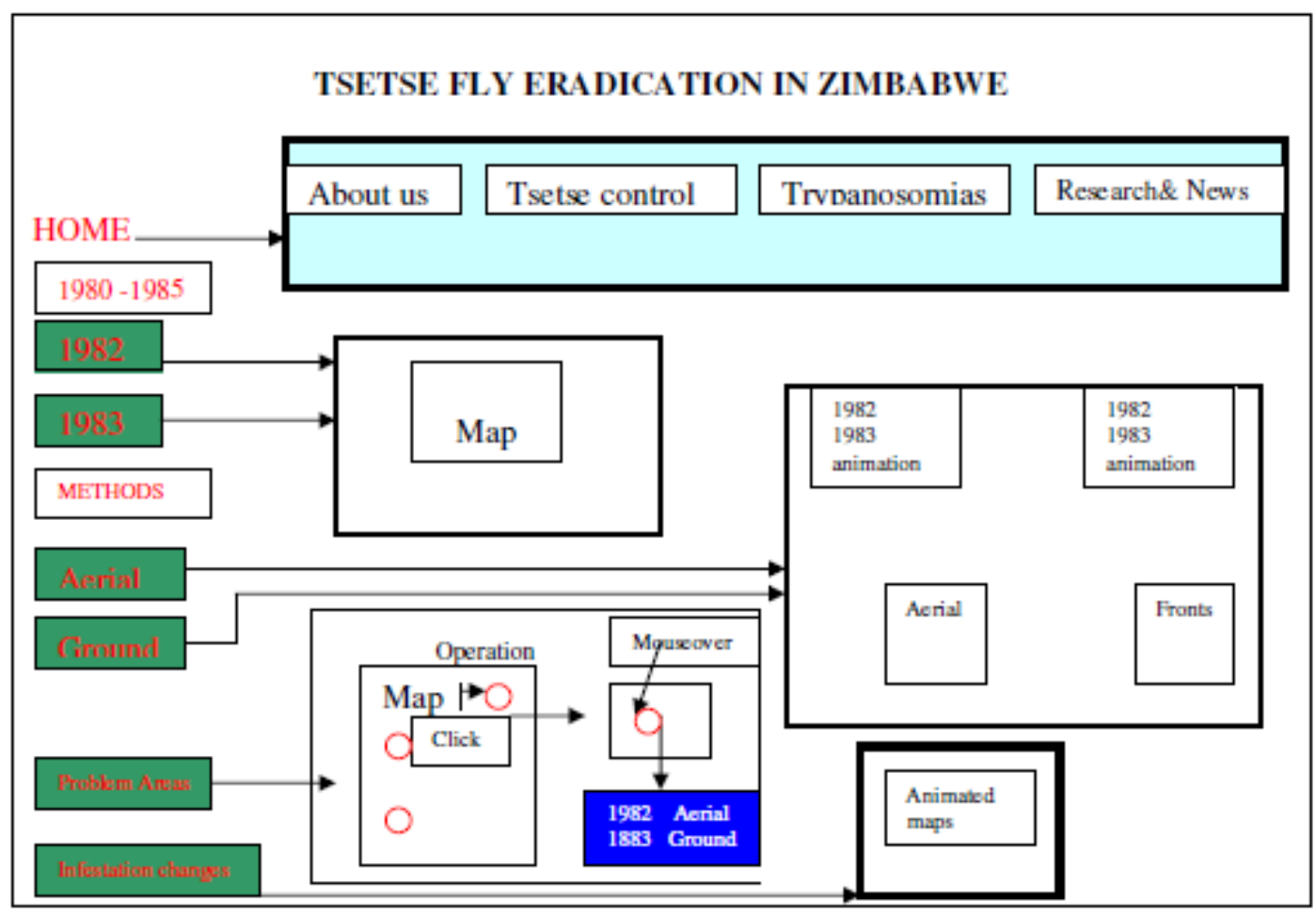

Figure 11: Navigation through tsetse fly eradication

\section{Navigation}

The order of contents does not control the order of what has to be viewed first. It has been done to keep related information together. Clicking on any item, opens a page containing information related to that item clicked.

HOME will lead to a page carrying information on tsetse control branch, (about us, Tsetse control, 
Trypanosomiasis, Research \& news, Contact us). To view the contents of the topics, one clicks on the word.

Bigger uncoloured labels are not linked but they just indicate the programme. What was done in that programme is viewed by clicking the topics or date under the programme (figure 11). To view $1980-1985$ eradication activities, the year in which the activity took place is clicked and a page containing the map showing infested area, reclaimed area, pre 1896 tsetse free zone and technique used are visualized. Where more information was linked to an area, information was supplied to that effect. The three programmes follow similar pattern.

The techniques section provides visualization of techniques individually and compare their location with previous or next fronts (figure 11). Selecting a technique will open a page where one would be free to select which year to view both from the technique and front sections.

Problem areas lead to a frameset carrying Zimbabwe map with three circles marked on problem area. On clicking a circle, a map showing the area with administrative districts, national parks and safari areas is displayed. On putting mouse over any circle on the map, a pop up message shows up carrying information on years and technique used on the spot for particular year, Figures 9 and 11.

Infestation changes leads to animation representation of fronts of period covered by the available data, 1981 - 1997 (figure 10). This enables visualisation of the eradication trend.

Besides the information that could be mapped, additional information on tsetse fly eradication and any other related to the eradication had been provided through links and behaviours like mouse over. Further visualization possibilities, like comparisons and animations have also been made possible. Accessibility to the information has been presented through the web following the structure of the operations, techniques used and the problem areas to carry out any research to find out why there is that resistance.

\section{Conclusion and Recommendations}

Tsetse flies have been a problem to the people for a long time. A lot has been written about their eradication but still more efforts are required to provide visualization possibilities of the information that pertain to the past and future eradication process. Analysis of the data from available literature revealed that a lot of data exists. From the available data, it was possible to visualize Zimbabwe in three distinct categories: infested, reclaimed and the area that had never been occupied by tsetse flies. Visualization of the processes was possible in three sections that identified the sequence of eradication. It has been possible to visualize the change in technology in terms of techniques used. The first section showed aerial and ground spraying being used, in second section an additional technology, targets was applied and the third section defensive measures to safeguard the gained areas were put in place. The areas where eradication of tsetse had taken place were identifiable by the location where different eradication techniques were applied. The changes in infestation could be visualized from fronts on multiple static maps, animated representation of each of the three 
programmes and animated representation of the whole period from $1980-1998$. Possibilities of analysing areas where particular techniques were applied were provided. It has been possible to get information on some insecticides applied by using mouse over behaviours.

From the type of data source used, the establishment of a digital system in the mapping section of the branch and disseminate the information on the web to improve accessibility and information sharing is recommend. It would also be possible to visualize hidden information like the insecticides used on particular places. This might be of interest to scientists to investigate its effects on other creatures such as fish. Besides information extraction, this will improve communication among interested parties.

\section{References}

Chadenga, V. (1992). Analysis of the efficacy, practicality and cost of various tsetse and trypanosomiasis control techniques as used in Zimbabwe

Child, G.F.T. and Riney, T. (1987). Tsetse control hunting in Zimbabwe 1919 - 1958, Zambezia, 1(4) issue 1

DuToit, T.J. (1997). Preliminary Environmental Assessment of tsetse fly eradication in Matusadona national park. http://www.africabib.org/htp.php ?RID=119547481 (accessed June 2016)
http://www.fao.org/docrep/004/T

0599E/T0599E08.htm (accessed July 2016)

http://www.afriaconline.co.zw/vet/tsetse. $\underline{\mathrm{html} / \text { trypanosomiasis.html }}$

http://www.fao.org/paat/html/body_bwa. $\underline{\mathrm{html}}$

http://www.encyclopedia.com/articles http://www.tdigroup.ie/review993

Kraak, M.J. and MacEachren, A.M. (1994). Visualization of the temporal component of spatial data, Pro. $6^{\text {th }}$ Int. symp. spatial data handling volume 1 pp $391-403$.

Kraak, M.J. and Ormeling, F.J. (1996). Cartography: Visualization of spatial data. Harlow, Essex: Addison Wesley Longman Limited.

Kraak, M.J. (2001). Visualize Overijssel's past interactive animation's on the WWW

Lovemore, F.D. (1999). Final report for Zimbabwe component of the first and second phases of regional tsetse and trypanosomiasis control programme Malawi, Mozambique, Zambia and Zimbabwe 1986 1988.

Shereni, W. (1984). The uses of cloth screen and acetone vapour as alternatives to a bait ox for sampling populations of tsetse flies (Diptera glossinidale) Transactions of the Zimbabwe Scientific Association. 62(4): $22-27$. 